\title{
THEORE'TICAL MODELING OF CREVICE AND PITTING CORROSION PROCESSES IN RELATION TO CORROSION OF RADIOACTIVE WASTE CONTAINERS
}

EGG-M--89197

DE91 001928

\section{Materials Research Society}

XIIth symposium on the Scientific Basis for Nuclear Waste Management Fall, 1989 Meeting

September 9, 1989

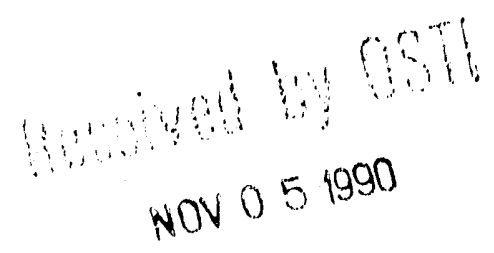

\author{
John C. Walton \\ Idaho National Engineering Laboratory \\ P.O. Box 1625 \\ Idaho Falls, Idaho 834:15 \\ Ph. 208-526-0320

\section{DISCLAIMER}

\footnotetext{
This report was prepared as an account of work sponsored by an agency of the United States Government. Neither the United States Government nor any agency thereof, nor any of their employees, makes auy warranty, express or implied, or assumes any legal liability or responsibility for the accuracy, completeness, or usefulness of any information, apparatus, product, or process disclosed, or represents that its use would not infringe privately owned rights. Reference herein to any specific commercial product, process, or service by trade name, trademark, manufactures, or otherwise does not necessarily constitute or imply its endorsernent, recommendation, or favoring by the Uniter. States Government or any agency thereof. The views and opinions of authors expressed herein do not necessarily state or reflect those of the United States Government or any agency thereof
}

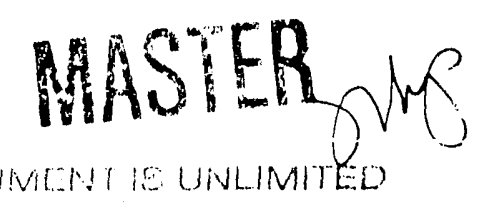




\section{Theoretical Modeling of Crevice and Pitting Corrosion Processes in Relation to Corrosion of Radioactive Waste Containers}

JOHN C. WALTON

Idaho National Engineering Laboratory, P.O. Box 1625, Idaho Falls, Idaho 83415

\section{ABSTRACT}

A mathematical and numerical model for evaluation of crevice and pitting corrosion in radioactive waste containers is presented. The model considers mass transport, mass transfer at the metal/solution interface, and chemical speciation in the corrosion cavity. The model is compared against experimental data obtained in artificial crevices. Excellent agreement is found between modeled and experimental values. The importance of full consideration of complex ion formation in the aqueous solution is emphasized and illustrated.

\section{MATHEMATICAL MODEL}

Safe disposal of radioactive wastes requires that the wastes be isolated ior long time periods. One component in many waste isolation schemes is a metallic container. The exact role of the container in the system can best be evaluated from a fundamental understanding of corrosion processes which occur and their controlling factors. To assist in this understanding, a model describing the electrochemistry in pits and crevices has been developed. The model is general in form and applicable to any number of metal/electrolyte systems. As a means of validation, the model is applied to recent experimental data from laboratory crevices of iron in different electrolytes.

Mass Transport The equation for transport of dissolved electrolytes in dilute solutions, subject to diffusion and electromigration is [1]:

$$
\vec{J}_{1}=-n D_{1} \vec{\nabla} C_{1}-\frac{n z_{i} D D_{1} F}{R T} C_{i} \vec{\nabla} \phi_{s}
$$

where:

$\vec{J}_{i}=$ flux of species $i$ in solution (moles $/ \mathrm{dm}^{2}-s$ )

$z_{1}=$ charge of species $i$

11 = liquid porosity in corrosion cavity

$D_{i}=$ diffusivity of species $i\left(\mathrm{dm}^{2} / \mathrm{s}\right)$

$\vec{\nabla}=$ vector gradient operator

$C_{i}=$ concentration of species $\mathrm{i}\left(\right.$ moles $\left./ \mathrm{dm}^{3}\right)$

$F=$ Faraday constant

$R=$ gas law constant

$\mathrm{T}=$ absolute temperature

$\phi_{\mathrm{S}}=$ potential in solution (volt)

A porosity term ( $n$ ) is included in the equations to allow for the situation where the corrorion cavity is partially filled with gas or solid phase corrosion products such as hydrogen gas, metal oxides, or salts. The liquid porosity is the proportion of the cavity volume which is filled with the liquid phase. When corrosion products are not present in the cavity, the porosity is equal to one.

Chemical Reaction Two types of chemical reactions are of interest in crevices and pits 1) electrochemical reactions at the metal;'solution interface and 2) reactions in the crevice solution (e.g., hydrolysis). The current density resulting from an electrochemical reaction at the metal/solution interface will generally be expressed as a function of the corrosion potential and the concentrations of some aqueous species (e.g., Butler-Volmer kinetics). The mathematical formulation of the model allows the use of any functional form of the current density expressions, including tabulated coefficients.

The rate of chemical reaction/mass transfer for each aqueous species at the metal/solution interface $\left(\mathrm{N}_{\mathrm{i}}\right)$ is ohtained from the current density of the electrochemical reactions using Faraday's law. 
Rates of reaction of species in the crevice/pit solution can be expressed in terms of kinetic expressions (e.g., first order kinetics) or adjusted arbitrarily to keep the reactions at equilibrium. In general, acid/base hydrolysis reactions are rapid, justifying the assumption of local equilibrium. If it is to be assumed that a reaction in solution remains at equiliz, "um, several distinct approaches can be used to formulate the system of equations. The most common method is to write out all the governing equations in rate format $[2,3,4]$ tinen add and subtract equations to eliminate the arbitrary rate expressions. The new set of governing equations are then supplemented by the equilibrium constants for the reactions remaining at equilibrium. This methodology is most clearly illustrated in the work by Sharland [4]. The disadvartages are that the governing equations generally must be rederived each time a new system is modeled or a new reaction is considered. Also these models tend to implicitly assume that any solid corrosion product included in the formulation will be present throughout the corrosion cavity.

An alternative methodology to model the equilibrium state in solution is to keep the governing equations in rate format but make the reaction rates very fast. As long as reaction rates are fast, relative to rates of mass transport, the reactions will remain at equilibrium and the solution is independent of the kinetics assumed. Any kinetic expression which is physically consistent ${ }^{6}$ (i.e., is stoichiometrically true, gives zero net reaction rate at equilibrium, changes sign as the equilibrium point is crossed, and gives fast reaction rates) can be used. The choice becomes a matter of numerical stability and convenience.

Keeping the equations in rate format allows the system of equations for the localized corrosion cell to be solved without requiring a priori algebraic manipulation of the governing equations. This greatly facilities adaptation of the model to different electrolytes and metals.

Governing Equations As a simplifying assumption, concentrations of species in the solution are assumed uniform in the cross-width directions. This assumption will be valid when the length of the cavity is significantly greater than the width (i.e., for crevices and relatively deep pits). A balance on a control volume taken as a slice of the model domain assuming steady state gives for each species:

$$
\frac{\partial C_{i}}{\partial t}=0=D_{1} \frac{\partial^{2} C_{1}}{\partial x^{2}}+\frac{Z_{1} D_{i} F}{R^{\prime} T} \frac{\partial}{\partial x}\left(C_{1} \frac{\partial \phi_{s}}{\partial x}\right)+\frac{N_{1}}{n W}+R_{1}
$$

where:

$\mathrm{W}=$ width of crevice $(\mathrm{dm})$

$\mathrm{x}=$ distance from mouth of crevice $(\mathrm{dm})$

$N_{1}=$ flux of species $\mathrm{i}$ at metal/solution interface (moles $\left./ \mathrm{dm}^{2}-\mathrm{s}\right)$

The governing equation for a deep cylindrical pit is similar to that for crevices:

$$
\frac{\partial C_{i}}{\partial t}=0=D_{i} \frac{\partial^{2} C_{i}}{\partial x^{2}}+\frac{z_{i} D_{i} F}{R T} \frac{\partial}{\partial x}\left(C_{i} \frac{\partial \phi_{s}}{\partial x}\right)+\frac{2 N_{i}}{n r}+R_{i}
$$

whrse:

$$
r=\text { radius of pit }(\mathrm{dm})
$$

Equation 2 (or 3 ) is written for each of the aqueous species being considered in the model system. Because the potential is also an unknown variable, another governing equation is required. The requirement is satisfied by the electroneutrality equation:

$$
\sum^{1} c_{1} z_{1}=0
$$


The boundary conditions at the cavity mouth are fixed concentrations and potential. At the base of the cavity the boundary conditions are $\mathrm{N}_{\mathrm{i}}=-\mathrm{J}_{\mathrm{i}}$ and electroneutrality. In the situation where the bottom of the cavity is non-metallic (e.g., many crevices) a boundary condition of zero gradient for all species is imposed.

To obtain a solution, the de rivatives are approximated by finite difference equations. The equations are then solved by relaxation [6]. An initial guess for all values is made at the grid points, then the numerical solution improved through iteration. To reduce the number of grid points needed for an accurate solution a variably-spaced grid is used with a greater concentration of nodes near the mouth where the highest gradients are present.

\section{MODEL VALIDATION}

Prior to the use of theoretical models in performance assessments it is important that the models be validated. Although mechanistic models are based on theory, which should work in the future as well as the present, they are of necessity simplifications of more complicated real systems. In this light, the model has been applied to recent experimental work on crevice corrosion of iron [7]. The experimental systems were for crevice corrosion of iron in electrolyte solutions of acetate buffer and sulfuric acid at $25^{\circ} \mathrm{C}$. The experimental apparatus $[7,8]$ consisted of a $5 \mathrm{~mm}$ long, $0.5 \mathrm{~mm}$ wide, and 10 $\mathrm{mm}$ deep crevice with iron metal on one side. Corrosion products were not allowed to build up extensively in the experiments considered herein, giving a porosity of 1.0. A perpendicular section of metal measuring $5 \mathrm{~mm} \times 20 \mathrm{~mm}$ was included on the surface. The systems were anodically polarized and the potential measured as a function of distance inside the crevice by insertion of a Luggin capillary.

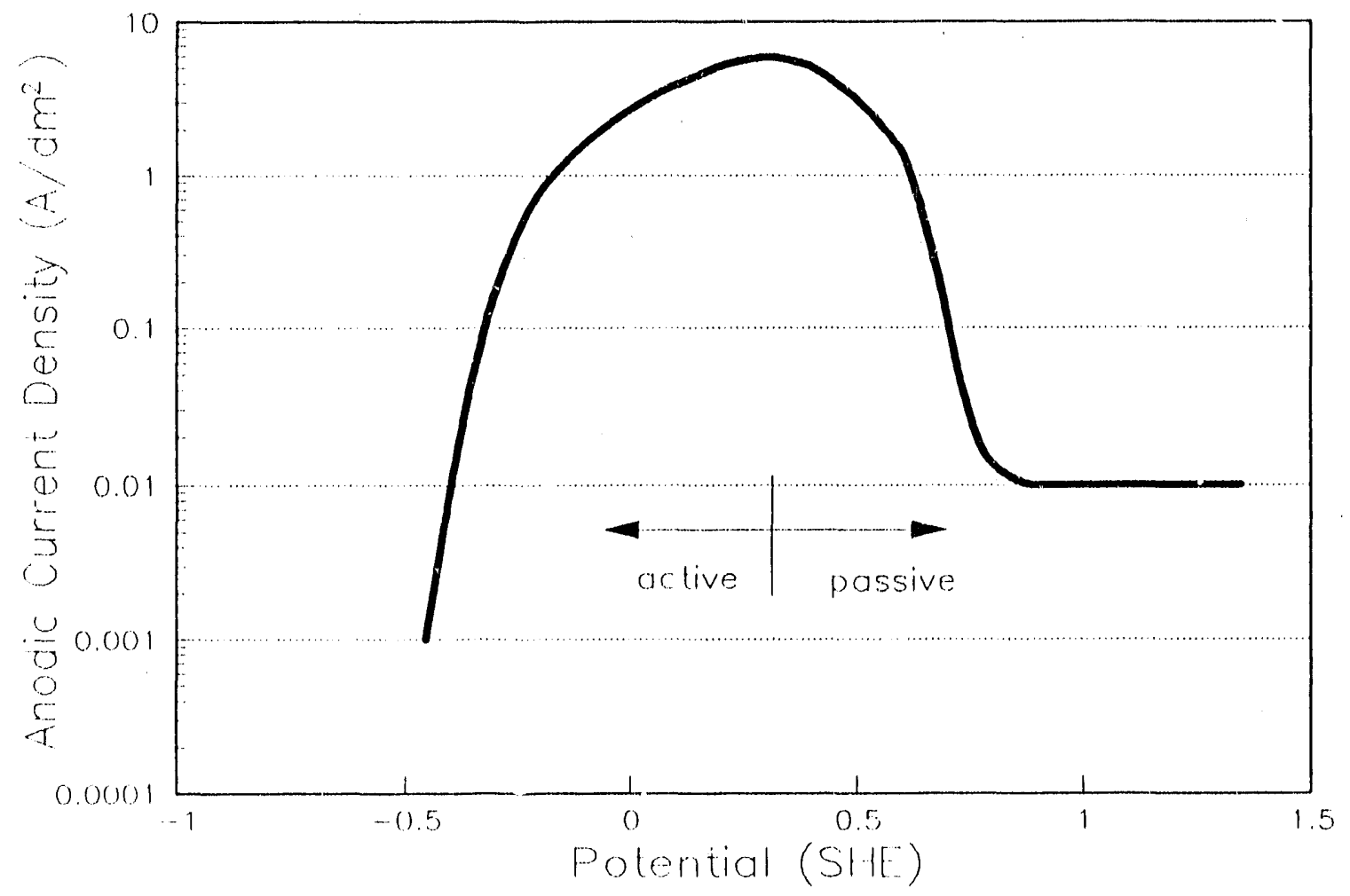

Figure 1. Anodic current density of uncreviced iron specimen in acetate solution as a function of potential.

The systems are of some interest [8] because active crevice corrosion was found in electrolytes which were designed to exclude aggressive anions and minimize localized acidity. Potential drops of over one volt were measured from the bulk solution to the base of the crevice. A more detailed explaination of this modeling work is given in a separate paper [9]. 
Acetate Electrolyte The acetate solution consisted of a mixture of equal amounts of $0.5 \mathrm{M}$ acetic acid solution and $0.5 \mathrm{M}$ sodium acetate solution. This forms a buffer solution of $\mathrm{pH} 4.8$.

The reactions considered in modeling the system are:

$$
\begin{aligned}
& \left.\mathrm{H}_{2} \mathrm{O}+\mathrm{Fe}^{2+}{ }_{(\text {aq })} \Leftrightarrow \mathrm{FeOH}^{+}{ }_{(\mathrm{aq})}+\mathrm{H}^{+}{ }_{(\text {aq }}\right) \\
& \mathrm{Fe}(\mathrm{OH})_{2}(\mathrm{~s})+2 \mathrm{H}^{+}(\mathrm{aq}) \Leftarrow \mathrm{Fe}^{2+}(\mathrm{aq})+2 \mathrm{H}_{2} \mathrm{O} \\
& \mathrm{H}_{2} \mathrm{O} \Leftrightarrow \mathrm{H}^{+}{ }_{(\text {aq })}+\mathrm{OH}^{-}(\text {aq }) \\
& \mathrm{CH}_{3} \mathrm{COOH}_{(\mathrm{aq})} \Leftrightarrow \mathrm{H}^{+}{ }_{(\mathrm{aq})}+\mathrm{CH}_{3} \mathrm{COO}^{-}(\mathrm{aq}) \\
& \mathrm{CH}_{3} \mathrm{COO}^{-}(\mathrm{aq})+\mathrm{Fe}^{2+}{ }_{(\text {aq })} \Leftrightarrow \mathrm{CH}_{3} \mathrm{COOFe}^{+}{ }_{(\mathrm{aq})}
\end{aligned}
$$

These reactions, with the exception of reaction 7 , are assumed to remain at equilibrium. Reaction 7 only becomes active if the solution becomes supersaturated with ferrous hydroxide. Eight aqueous species and the potential are considered in the model.

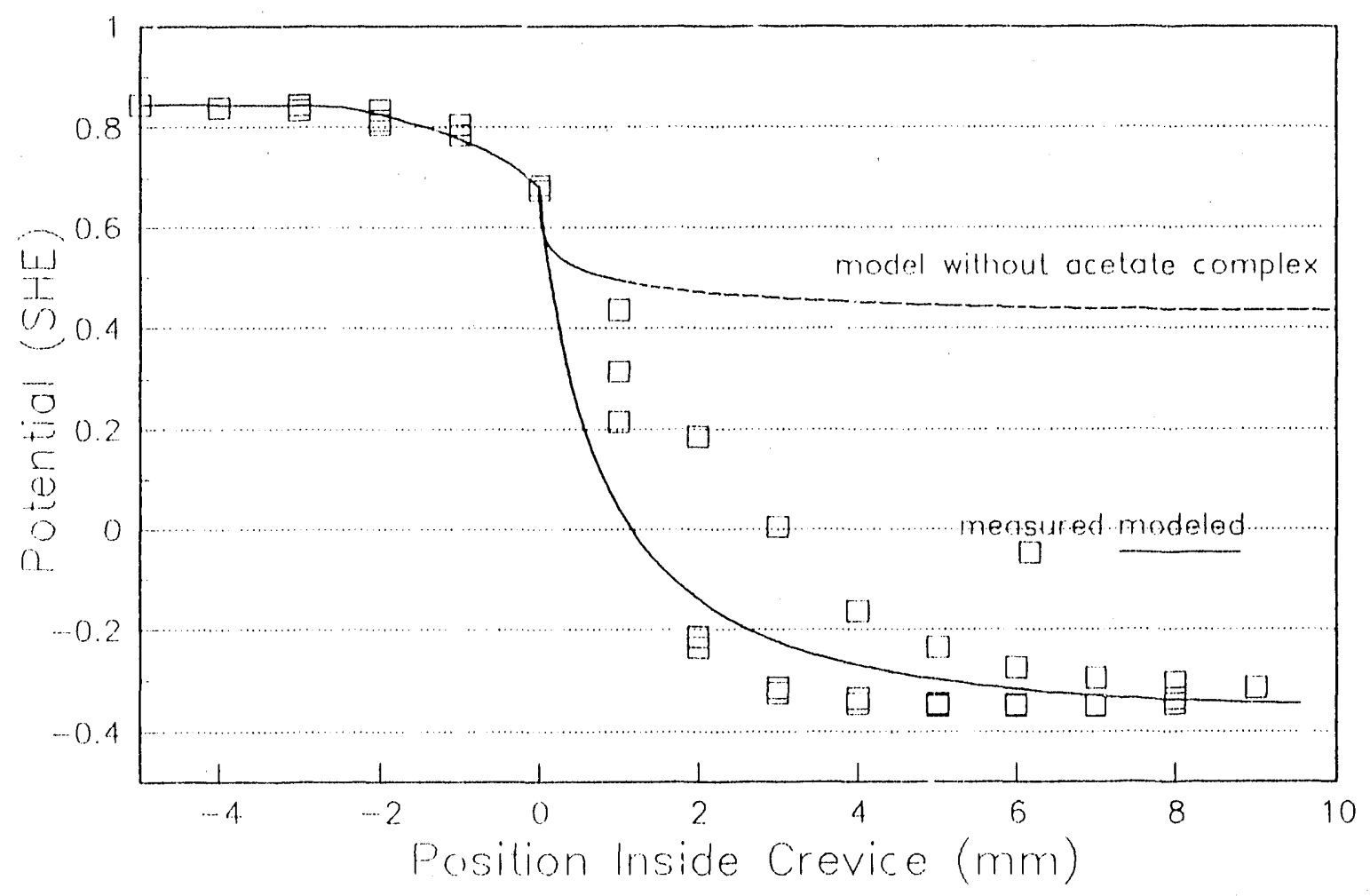

Figure 2. Predicted and measured potentials from crevice in acetate solution polarized at $0.844 \mathrm{VSHE}$. The negative distances refer to measurements outside the crevice mouth. The data points represent the results from several experiments.

Electrochemical kinetics in the occluded cell are described by polarization data for an uncreviced sample of iron in the same solution (Figure 1). The polarization curve is discretized into a series of (current,potential) data pairs for use in the code. Intermediate values are estimated assuming a linear relation between the log of the current density and the potential. The system always remains above the rest potential for the active metal. Thus only the anodic polarization curve is required.

In the experiments, significant potential drops were found in moving through the external solution to the crevice mouth. The potential drops in the bulk solution, outside the occluded cell, are not within the scope of the modei presented herein but are e:aluated for the sake of completeness. Potential drops in the bulk solution, where concentration gradients are expected to be smail, can be estimated using Ohm's law. Application of Ohm's law leads to Laplace's equaiion for the potential [1]. 


$$
\vec{\nabla}^{2} \phi_{s}=0
$$

Boundary conditions are the measured potential at the crevice mouth, the applied potential at distance in the solution, and $\partial \phi / \partial x=0$ on the exposed metal surface. Laplaces equation is solved for the wo dimensional geometry outside the crevice using the computer code PORFLO [10], which was designed for groundwater applications.

The model predicts the potential, current density, and electrolyte composition as a function of distance inside the occluded cell. A comparison of measured and predicted potentials for the system polarized to $0.84 \mathrm{~V}$ (SHE) is given in Figure 2. The agreement is cuite good. The active/passive transition occurs inside the crevice with the most rapid corrosion rate occurring just below this point. The predicted distribution of anodic current (Figure 3) is consistent with the observed corrosion rate of the specimens and the observed location of the active/passive transition $[7,8]$.

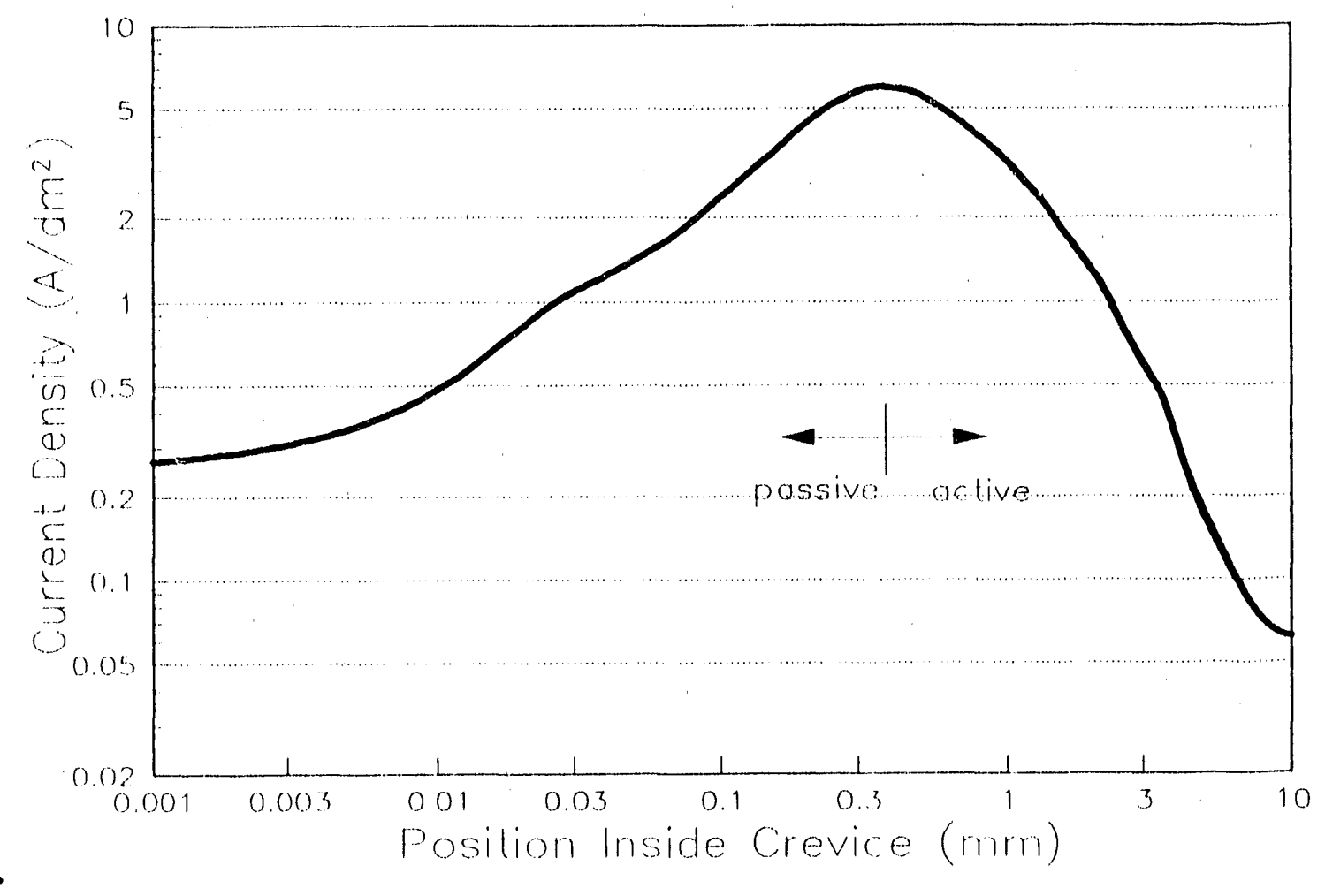

Figure 3. Predicted current density inside experimental crevice. Note location of active/passive transition.

Most of the iron is tied ' $p$ in the acetate complex. This minimizes the amount of iron hydrolysis. In the absence of significant metal hydrolysis, the hydrogen ions move rapidly out of the crevice as a result of the large potential gradients. The system never reaches saturation with respect to ferrous hydroxide.

Another set of experiments was performed at a polarization of $1.24 \mathrm{~V}$ (SIIE). The comparison between modeled and measured potentials is given in Figure 4. Polarization at a variety of other potentials indicated that the potential at the base of the crevice varied very little. Irrespective of the external anodic polarization, the base of the crevice tended toward the same "limiting" potential $\left(\mathrm{E}_{\mathrm{lim}}\right)$. The model also predicts that potentials at the base are nearly independent of the mouth potential.

The importance of detailed speciation of the crevice solution is illustrated in Figure 2. As an exercise, the acetate complex, which ties up most of the ferrous iron in the crevice solution was omitted from the model formulation. Note that with this omission the model greatly underpredicts the potential drop inside the crevice. 


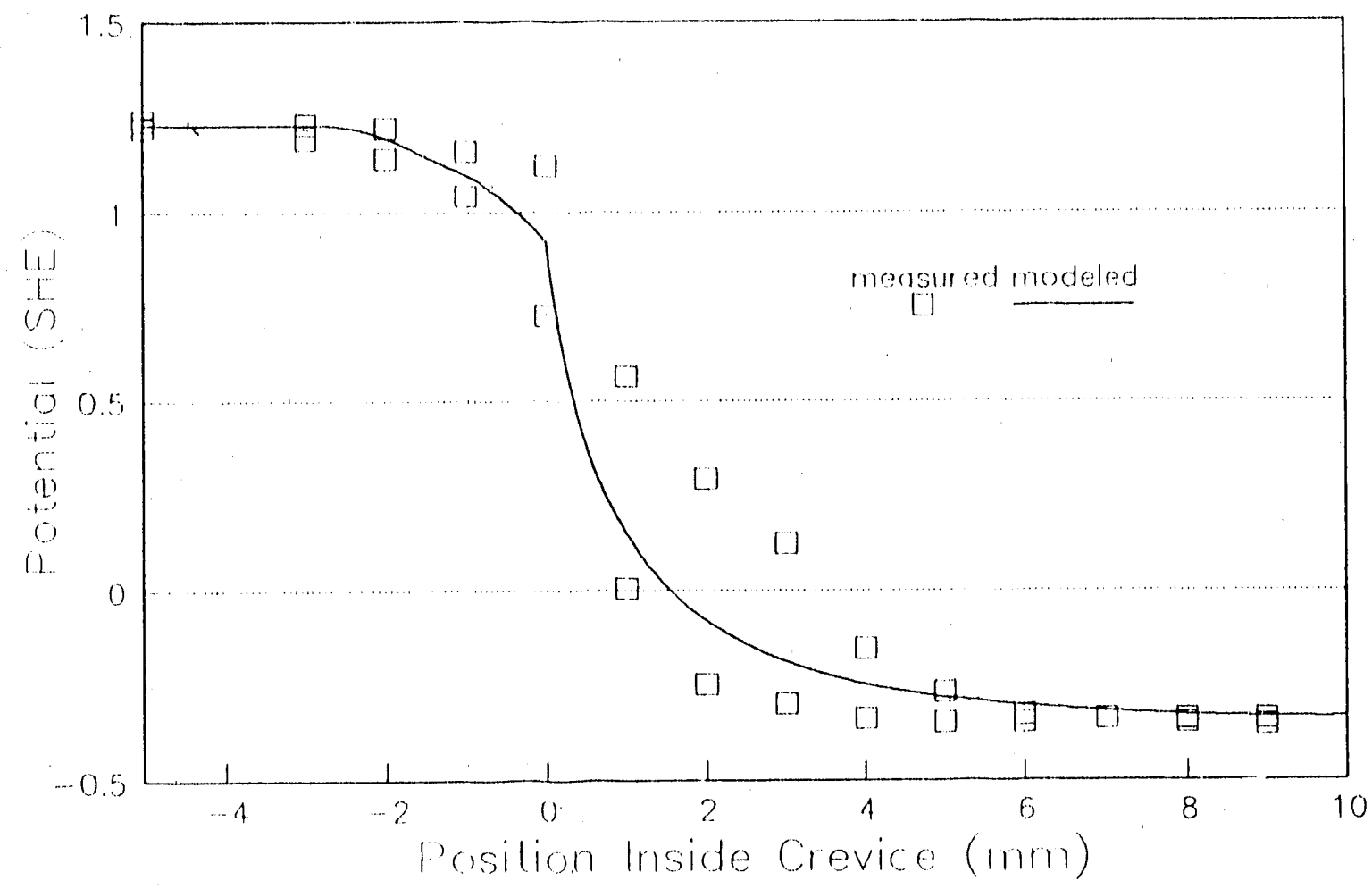

Figure 4. Predicted and measured potentials from crevice in acetate solution polarized at 1.24 V SHE. The negative distances refer to measurements outside the crevice mouth. The data points represent the results from several experiments.

Sulfuric Acid Electrolyte The sulfuric acid solution consisted of $0.001 \mathrm{M}$ sulfuric acid. The reactions considered in modeling the system are:

$$
\begin{aligned}
& \mathrm{H}_{2} \mathrm{O}+\mathrm{Fe}^{2+}{ }_{(\mathrm{aq})} \Leftrightarrow \mathrm{FeOH}^{+}{ }_{(\mathrm{aq})}+\mathrm{H}^{+}{ }_{(\mathrm{aq})} \\
& \mathrm{H}_{2} \mathrm{O} \Leftrightarrow \mathrm{H}^{+}{ }_{(\text {aq })}+\mathrm{OH}^{-}{ }_{\text {(aq) }} \\
& \mathrm{FeSO}_{4} 7 \mathrm{H}_{2} \mathrm{O}(\mathrm{s}) \Leftrightarrow \mathrm{Fe}^{2+}{ }_{(\mathrm{aq})}+\mathrm{SO}_{4}{ }^{2-}{ }_{(\mathrm{aq})}+7 \mathrm{H}_{2} \mathrm{O}
\end{aligned}
$$

These reactions, with the exception of reaction (13), are assumed to remain at equilibrium. Reaction (13) only becomes active when the solution becomes supersaturated with ferrous sulfate. Five aqueous species and the potential are considered in the model.

As with the acetate solution, the boundary conditions are fixed concentrations and potentials at the mouth and zero gradient at the base. The kinetics were nbtained by discretization of the anodic polarization curve obtained from an uncreviced sample in the same solution [7].

The model predicts the potential and electrolyte composition as a function of distance inside the occluded cell. A comparison of measured and predicted potentials is given in Figure 5. Ferrous sulfate is predicted to precipitate at the base of the crevice. The potential at the crevice base in sulfuric acid solutions also reached a limicing value at depth which was independent of the degree of anodic polarization in the experiments.

As an illustration of the importance of the composition of the crevice solution, ferrous sulfate was not allowed to precipitate in one model run (Figure 5). lgnoring precipitation of ferrous sulfate results in an underestimate of the potential drop in the corrosion cavity. 


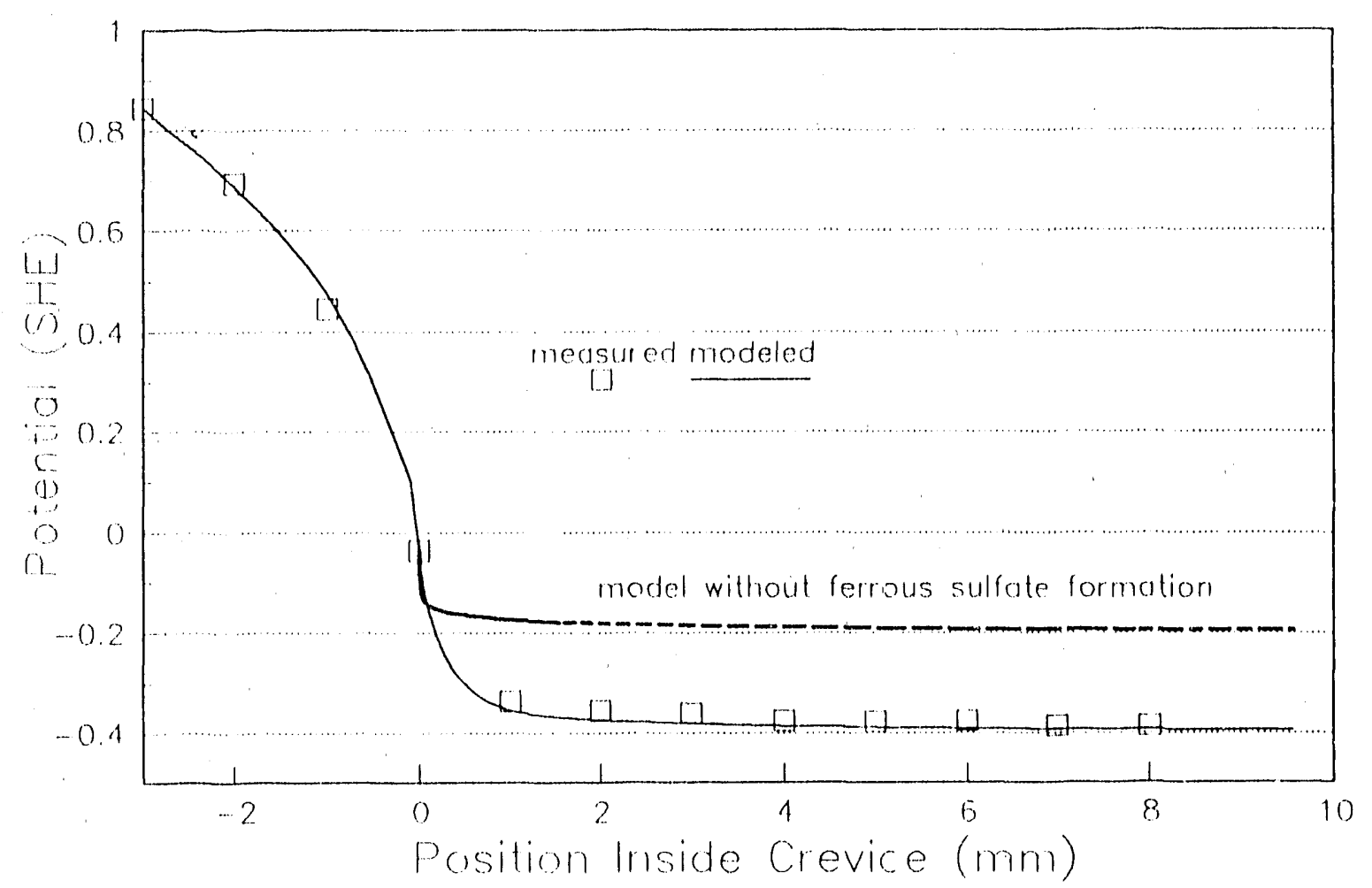

Figiıre 5. Predicted and measured potentials from crevice in sulfuric acid solution polarized at $0.844 \mathrm{VSHE}$. The negative distances refer to measurements outside the crevice mouth.

\section{CONCLUSION}

In summary, a conceptual, mathematical, and numerical model of the electrochemistry in crevices and pits has been developed. The model was used to predict the electrochemistry in several laboratory systems. Model input was based upon literature values of transport properties for the ions of concern and kinetic data from uncreviced specimens. Comparison of modeled and measured data showed excellent quantitative agreement. No empirical scaling factors or adjustments to the theoretical constructs of the model were required to explain or predict the real system. This result gives strong support to the application of models based upon first principles to assessment of radionactive waste disposal systems.

The importance of detailed speciation in predicting the potential drops was illustrated with numerical examples. Omission of important reactions tends to cause underprediction of the potential drop inside the cavity. Underpredictions of the potential drop in turn cause overpredictions of the anodic current density at depth in the corrosion cavity.

Theoretical models of localized corrosion can do a good job of predicting the electrochemistry in some simplified experimental systems. Much research remains to be performed before they can be used with confidence to predict more complex corrosion systems. Clearly these models are necessary to complement and guide empirical work on corrosion rates because of the unique conditions of waste isolation systems: limited mass transport rates, and long time periods of concern.

\section{ACKNOWLEDGMEN'T}

The assistance of Dr. S. A. Rawson is gratefully acknowledged. Work partially funded under the auspices of the U.S. Department of Energy, DOE Contract No. DE-AC07-76IDO1570. 


\section{REFERENCES}

[1] Newman, J., Electrochemical Systems, Prentice Hall, New Jersey, (1973).

[2] Turnbull, A. and J. G. N. Thomas, J. Electrochem. Soc., 129(7), p. 1412, (1982).

[3] Gravano, S. M., and J. R. Galvele, Corrosion Science, 24(6), p. 517, (1984).

[4] Sharland, S. M., Corrosion Science, 28(6), p. 621, (1988).

[5] Lasaga, A. C., and R. J. Kirkpatrick, Kinetics of Geochemical Processes, Mineralogical Society of America, Washington, (1981).

[6] Press, W. H., B. P. Flan.ıery, S. A. Teukolsky, and W. T. Vetterling, Numerical Recipes - The Art of Scientific Computing, Cambridge University Press, New York, (1985).

[7] A. Valdes-Moldon, Ph.D. thesis, The Pennsylvania State University, (1987).

[8] Pickering, H. W., Corrosion Science, 29(2/3), p. 325, (1989).

[9] Walton, J. C., Corrosion Science, (in press).

[10] Runchal, A., B. Sagar, R. G. Baca, and N. W. Kline, PORFLO - A Continuum Model for Fluid Flow, Heat Transfer, and Mass Transport in Porous Media: Model Theory, Numerical Methods, and Computational Tests, Rockwell Hanford Operations, RHO-BW-CR-150-P, (1985). 

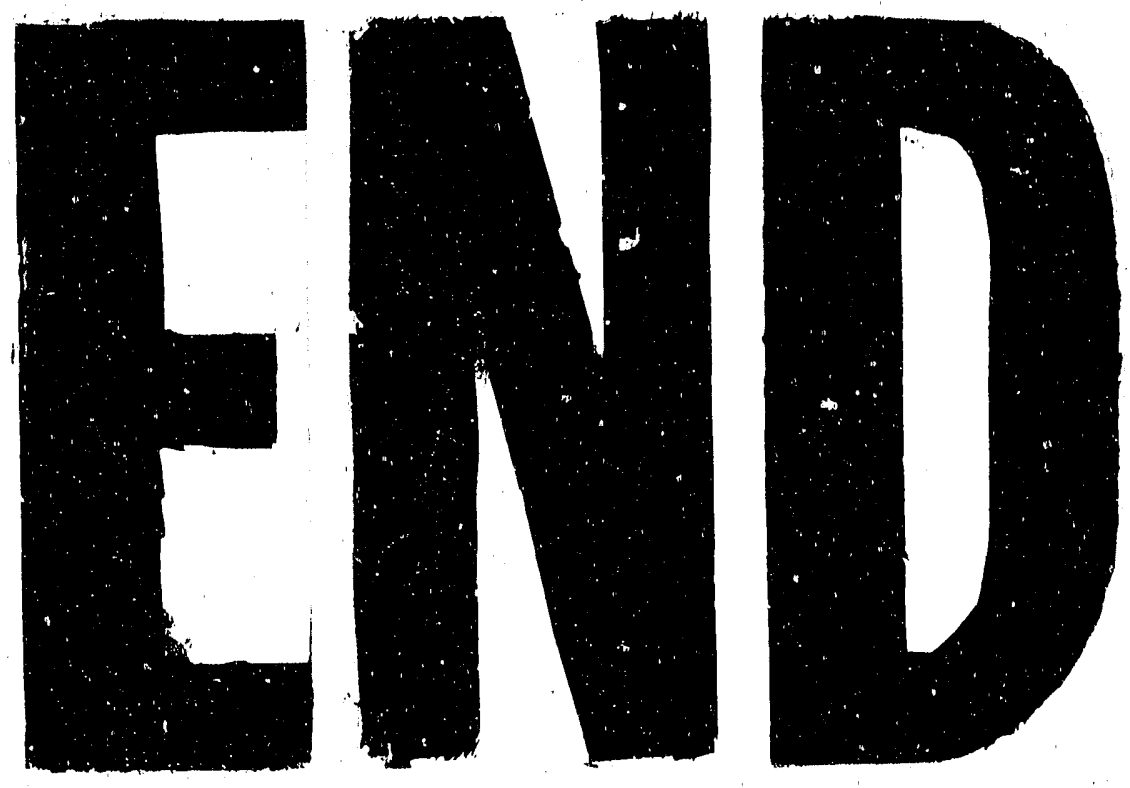

4
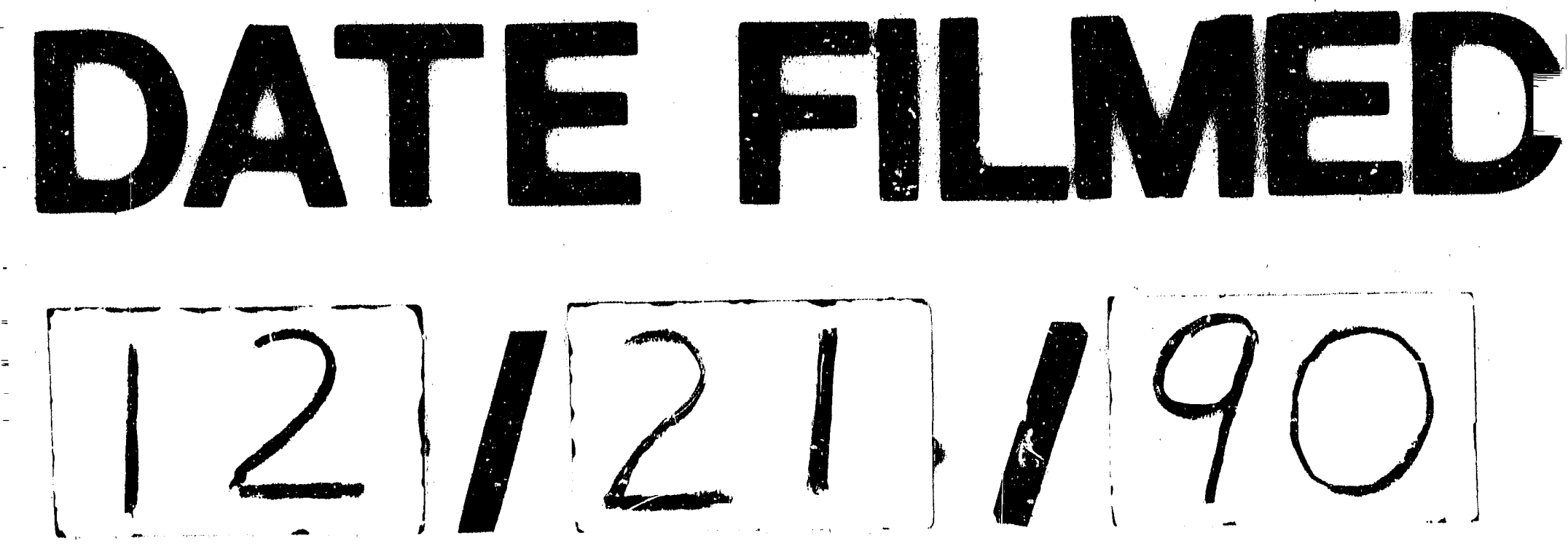
